\title{
Institutionalizing Scientific Knowledge: The Social and Political Foundation of Empirical Economic Research
}

\author{
Werner Reichmann* \\ Max Planck Institute for the Study of Societies
}

\begin{abstract}
Scientific knowledge is an essential component of modern society. Consequently, sociologists are interested in its production process and have conducted a broad variety of studies showing how social patterns influence the definition and the boundaries of scientific knowledge. In this paper, I ask how social factors influence the transformation of a 'normal' field of knowledge into a 'scientific' one. First, I give a brief overview of the development of the sociology of scientific knowledge exploring different approaches to the social foundations and boundaries of scientific knowledge. Second, I present a case study of the transformation of empirical economic research in the 1920s from a field of knowledge produced by journalists and civil servants into a prestigious scientific domain. I use neo-institutionalist ideas to show that knowledge needs a socially legitimated organizational frame in order to count as 'scientific' and I examine how political needs to 'manage the economy' build boundaries around economic knowledge and define it as 'scientific' in order to control its production, distribution, and communication.
\end{abstract}

\section{Under what conditions does knowledge become 'scientific knowledge'?}

Scientific knowledge has become increasingly influential, indeed vital for economic growth and for both technological and social change within contemporary society. Since the 1960s sociologists have characterized contemporary societies as 'knowledge societies' and analyze scientific knowledge as the basis of democratic political regimes (Lane 1966), of social stratification (Bell 1973), and economic innovation (Drucker 1993). At the same time the production of scientific knowledge became big business (de Solla Price 1963) employing more and more people. It was claims such as these that lead a number of sociologists to argue that contemporary societies are knowledge societies (Stehr 1994). When scientific knowledge becomes important for social life the definition of what is science and what not becomes crucial. In this paper, I want to show how social factors influence the classification of certain kinds of knowledge as 'scientific'. The main questions are: Under what social conditions will knowledge be labelled scientific? What are the sociopolitical grounds for constituting knowledge as both a product and a part of a scientific discipline? What actions transform non-scientific knowledge into a part of a scientific discipline? The assumption that scientific knowledge has social foundations might seem strange to some. Isn't it the case that scientific knowledge simply has to be 'true' in order to be called 'scientific'? Sociologists of science negate this question and undermine the claim that knowledge can be scientific 'by nature'. In this paper, I show the way in which 'normal' knowledge turns into scientific knowledge by analyzing the development of empirical economic research, which was the work of non-scientists until c. 1910. Not until specific social conditions were met in the 1920s did empirical economic research come to be understood as part of a scientific discipline, namely economics. 


\section{The social basis of scientific knowledge}

The sociology of science is a broad and diverse field which includes a number of competing schools and approaches (Hess 1997). I shall therefore first provide a brief overview of a related subfield, namely the sociology of scientific knowledge (or SSK) and focus on some relevant implications for the questions raised above.

In traditional philosophy, especially if you look at the positivistic approach, the creation of scientific knowledge is viewed as a matter of rational, cognitive, technical, and in some ways 'black boxed' procedure undertaken by scientists. Philosophers of science take it upon themselves to explore and develop the methods of science. Their understanding of science as self-contained and at the same time universal clearly emphasizes the autonomy of the scientific from the social realm. The assumption that there is just one scientific method and only one 'truth' prevents science from being determined socially.

In contrast, SSK leaves the claim of a special ontological status of scientific knowledge behind and focuses on the relationship between epistemic and social orders. It aims to explain the complex interdependencies between social and scientific logics, and raises the question of the penetration of social patterns into scientific strategies of explanation and understanding. Thus, scientific knowledge is no longer thought of as an enclosed and autonomous domain separated from other areas of society, but it is opened out and analyzed in terms of social patterns.

It was Karl Mannheim (1929) who in the first half of the 20th century first proposed a sociological foundation of knowledge in general, but he did so without reference to scientific knowledge. Robert K. Merton, often mentioned as the founding father of the sociology of science, focused on the social structure, the norms and values of western scientific communities and described the 'scientific ethos' (Merton 1938). Merton interprets science as an institution in a very broad sense of the term. An institution in sociological terms is a social entity in which there is a shared set of values and norms. The social unit, including its inner order, follows the values and norms and - at the same time - produces and re-produces them. Following this approach, institutional norms like universality, communality, organized scepticism, and disinterestedness lead to knowledge production (Merton 1938, 327). With the publication of Thomas Kuhn's The Structure of Scientific Revolutions (1962), which examined the process of scientific advances, a new era in analyzing scientific knowledge and its production began. He focused on the progress and advancement of science through the introduction of a specific concept called 'paradigm shift'. Paradigms, Kuhn argued, are agreements concerning thinking and acting within scientific disciplines. These agreements are challenged by 'anomalies' which subvert the prevailing tradition of scientific practice and thinking. When enough 'anomalies' have accumulated the old paradigm is replaced by a new one. Thus, Kuhn explains the progress of science not in terms of an internal scientific logics or rational factors, but as the outcome of the negotiation of social standards. Scientific knowledge no longer exists as something given and natural. Kuhn's thesis on the progress of science was widely and controversially discussed, and itself constituted something of a paradigm shift in our understanding of scientific practices.

The next important step in SSK was the appearance of David Bloor's book Knowledge and Social Imagery (1976) where he formulated the so-called 'Strong Programme' of SSK and developed new ideas about the origin of scientific knowledge. This approach is 'strong' because the idea that scientific knowledge is socially 'constructed' was radically applied to the natural sciences (Brannigan 1981) and even to mathematics (for a discussion of the different uses of the term 'social construction', see Sismondo 1993). With the 
strong programme we move from the 'standard view of science' to the 'new philosophical view of science' (Mulkay 1979). The former has its roots in the Mertonian institutionalist ideas. The latter denies that universal social norms define scientific knowledge (Knoblauch 2005, 243-4). On the latter view, it is the scientific subject who plays an active part in the knowledge production process. She interprets and selects, and therefore not merely describes nature but actively constructs it. The Strong Programme sparked intense debate and led to a number of empirical research programmes. The so-called 'Edinburgh School' showed that the production of scientific knowledge is connected to the interests of social classes. Using historical studies of debates and controversies between scientists, the Edinburgh School showed that the competing theories where represented by scientists who shared social networks and social class membership (Barnes and MacKenzie 1979; Barnes and Shapin 1979). Donald MacKenzie (1981), for example, examined how theoretical statistics became a scientific discipline between 1865 and 1930 . Using the biographies and the social positions of the three central actors in the development of statistics (Francis Galton, Karl Pearson, and Ronald A. Fisher), MacKenzie analyzed the relationship between British society and statistical theory in that period. The fact that all three protagonists were 'eugenists', and therefore had common ideas about how to 'improve' society, influenced their scientific theories significantly. As a result, science for MacKenzie is 'goal-oriented' (MacKenzie 1981, 225). These goals are the result of social interests; therefore 'scientific knowledge is constitutively social' (MacKenzie 1981, 225).

The idea of the social construction of scientific knowledge inspired another empirical programme which deals with the construction process itself - with 'science-in-the-making' (Latour and Woolgar 1979, 44). Taking 'the anthropologist as resource' (Hess 1997, 150), this approach also considers the materiality of the production of scientific knowledge: the places and objects that are connected to micro sociological processes and practices. Two 'spaces' of science became central to inquiry. On the one hand the uses of scientific experiments were the objects of interest (cf. Collins 1975; Gooding et al. 1989; Pickering 1984; Shapin and Schaffer 1989). On the other hand the scientific laboratory became the central 'space' for the social production of scientific knowledge, the interweaving of social and scientific practices and of the 'co-production' (Jasanoff 2004, 13-45) of epistemic and social orders (cf. Knorr 1977; Knorr Cetina 1981; Latour and Woolgar 1979; Lynch 1985; Zenzen and Restivo 1982). This radically empirical approach was the result of the sociological view that 'philosophy being philosophy was not interested in the empirical question of how knowledge was produced' (Knorr Cetina 2007, 362) and introduced some major innovations that have re-configured our picture of science and scientific knowledge permanently. The idea of conducting ethnography in academic institutions (Hess 1997, 152) produced an examination of science that systematically considered 'cultural' patterns (Knorr Cetina 1995). The assumption was that science and scientific knowledge can be characterized by distinct cultures of practice just like those we know from everyday activities and everyday knowledge: the concept of 'epistemic cultures' was born (Knorr Cetina 1999).

Another author whose work was based on an anthropological approach is especially relevant to the research question raised in this paper. In his study of the social construction of knowledge about the possibilities of breeding scallops in a bay in France, Michel Callon (1986) describes the construction of scientific knowledge as a 'translation' of the social and the natural into scientific notions and representations. He construes a network with all relevant actors (scientists, scientific community, fishermen, and scallops) and shows how the scientists arrange each actor and the network into a whole in order to 
impose their definition of the situation. Callon conceptualizes four 'moments' of translation: the first step is called 'problematization' (Callon 1986, 203) and should convince the whole network of actors and objects to accept that the way toward the solution of the problem leads through an 'obligatory passage point' (Callon 1986, 204). The two steps of 'intéressement' and 'enrolment' help to assign defined roles to actors and to ensure that they identify with them. The last step of translation is the 'mobilization' of representative spokespersons for every group of actors. In the end the scientists in Callon's study fail to ensure the translation. Both the scallops and some of the fishermen leave the roles assigned to them and so the process of production of scientific knowledge fails. For Callon the production of scientific knowledge is characterized as a process of 'structuring power relations'. The production of scientific knowledge is successful only as long as the scientists prevail in allocating views and roles to the actors and to the network.

To conclude, SSK proposed that we abandon some of the traditional views of scientific knowledge and the epistemic process. The methodological unity and universality of scientific knowledge gives way to the notion of an interest-based and socially determined particularism. A series of so far unquestioned dichotomies are challenged: science and society are no longer separate worlds but have to be analyzed together; truth, the criterion and goal of science par excellence, is now brought into a close relationship with social patterns; the scientific autonomy is now 'contaminated' with social interests, political views, and cultural patterns; rationality, as an instrument of perception, gives way to social negotiations (e.g. Evans 1999). Without doubt, all these innovations contribute to the demystification of science.

\section{The 'scientification' of economic knowledge}

As we can see in this brief overview of some of the main approaches in SSK, the natural sciences are the focus of most of the studies. However, to illustrate how a field of knowledge is transforms from 'normal' to 'scientific', I use here the case of a subfield of economics: empirical economic research (known in the German-speaking world as Konjunkturforschung; lit. research into business cycles).

Between 1910 and 1930 empirical economic research institutes were founded across the world (for a history of the institutions and main theoretical concepts of empirical economic research, see Coenen 1964). These institutes dealt with macroeconomic analysis, economic forecasting, and consultation for policy makers. They still exist and have a stable position in the scientific and political landscape of western-industrialized countries. The most famous ones are the US-American National Bureau of Economic Research (NBER), which was founded in 1920 (Fabricant 1984), the Institut für Konjunkturforschung, founded in Berlin 6 years later (Krengel 1986; Kulla 1996), the Österreichisches Institut für Konjunkturforschung, initially led by Friedrich von Hayek in Vienna (Reichmann 2010) and the British National Institute of Economic and Social Research, founded in London in 1938 (Jones 1999).

These institutions show some conspicuous similarities. First, even though they were founded as consultancies for political bodies, they did all they could to ensure their political independence. Secondly, even though the institutions were not formally affiliated to a university, they attached great importance to close collaboration with academic researchers. Thirdly, they strictly emphasized the scientific character of their work (Rutherford 2005, 110). Finally, political organizations across the whole political spectrum supported the foundation of the research departments and spent money to ensure their successful and sustainable establishment (Reichmann 2007). Clearly, political institutions had vital 
interests in creating institutions that can provide reliable knowledge on economic developments. The foundation of empirical economic research institutions is a clear example of the social transformation of a field of non-scientific knowledge into a strictly scientific domain. What had been the province of non-scientists (civil servants and journalist) prior to the 1920 s became the specialist science of economic research and forecasting. A significant change of the social conditions led to a re-definition of the knowledge.

In the following section, I discuss two possible approaches to understanding the transformation of the knowledge of empirical economic research into a scientific realm. First, I shall focus on neo-institutionalist arguments to show that scientific knowledge needs a socially legitimized organizational frame. Second, I shall analyze the interdependence of political needs with the 'scientification' of knowledge.

\section{The organizational framing of scientific knowledge}

For knowledge to be accepted as scientific it needs to be framed within a socially legitimated organization. In his historical account of the development of sociology, Edward Shils (1970) identified a set of conditions necessary to determine whether or not a field of knowledge may be called 'scientific'. He called the transformation of a field of knowledge into science the 'institutionalization' of an intellectual activity (Shils 1970, 763). By that he meant 'the relatively dense interaction of persons who perform that activity' and noted that 'the more intense the interaction, the more its structure makes place for authority which makes decisions regarding assessment, admission, promotion, allocation' (Shils 1970, 763). Shils went on to argue that:

The high degree of institutionalization of an intellectual activity entails its teaching and investigation within a regulated, scheduled, and systematically administered organization. The organization regulates access through a scrutiny of qualification, provides for organized assessment of performance, and allocates facilities, opportunities, and rewards for performance-for example, study, teaching, investigation, publication, appointment, and so forth. It also entails the organized support of the activity from outside the particular institution and the reception or use of the results of the activity beyond the boundaries of the institution. An intellectual activity need not be equally institutionalized in all these respects. (Shils 1970, 763)

Shils' seven necessary criteria were: first, there must be something like an intellectual and research activity that, on the one hand, excludes pure teaching activities and, on the other, assumes that in western industrial societies scientific knowledge is based on a specific cognitive activity. Second, and this is the most important point, Shils claims that those who conduct this intellectual activity have to communicate and interact with each other. The higher the density of interaction the higher the degree of institutionalization of a knowledge field. Third, the interactional structure within an institutionalized knowledge field develops a system that regulates the entry into the field and allocates its resources. In scientific fields the interactional and communicational structure works like a 'gatekeeper'. It defines and re-defines who is allowed to enter and who is forced to keep out. Fourth, there must be at least one regular and relevant publication organ that can be used as a medium of communication. A field of knowledge obtains the scientific status when there is, fifth, a formal administration behind the interactional structure and, sixth, the structure of communication is systematically extended to a group of successors in the field. The final point means that teaching students is also a part of the 'scientification' of a field of knowledge. Last but not least, the funding of a scientific discipline is different to the funding of a non-scientific field of knowledge. The former is funded by sources 
other than the researchers themselves. The latter is funded by the researchers themselves, by patronage, by amateurs, or by enthusiasts.

What Shils presents here is a typical sociological description of an institution. He lists concrete norms valid for a social entity, in this case, the norms for a field of knowledge to count as 'scientific'. The emphasis upon the influence of the institutional frame seeks to demonstrate that it is not a matter of the body of knowledge, its ontology, its structure, its 'nature', or its context of discovery that determines whether knowledge is scientific or not. It is - and this is the main argument here - a question of the social legitimation of the institutional framing.

The foundation of empirical economic research as a scientific concern illustrates what Shils calls the institutionalization of science. It is important to recognize that what the empirical economic research institutions did in their foundation phase had been done previously but in different forms and with different actors: amateurs, journalists, government officials, and civil servants. However, they had only tentative connections to academic and scholarly researchers and no specific training in economics. They had no consistent organizational support, had only loose contacts to each other, and - lacking a commonly accepted journal - used very heterogeneous communication media. They had no students and anybody could decide to be an empirical economic researcher. Without doubt they did intellectual work, but it was not legitimately institutionalized - so it was not scientific. I will call this type of engagement with economic issues 'pre-institutionalized' empirical economic research (for an overview of publications of pre-institutionalized empirical economic researchers in the German-speaking countries, see Reichmann 2010, 82-3). The work of pre-institutionalized empirical economic research was closely akin to what the economic research institutions founded in the 1920s did. Their outputs looked fairly similar; they used the same sources for their empirical data, the same underdeveloped body of theory, and the same methodological tools. The key difference was that the intellectual activity was framed differently in its pre-institutionalized and its institutionalized phase. Only in the 1920s was empirical economic research pressed into the social framing which was legitimatized; only then did it became part of the scientific community and was acknowledge as a source of 'scientific' knowledge.

\section{The cultural foundation of organizational frames}

Now we know that the production of knowledge needs a specific social frame to be legitimated as 'scientific'. But at this point a new question arises. Of all the possible criteria of scientificity, why does Shils' select these seven? History shows that the social demands on the social framing of scientific knowledge are not stable but are in permanent flux. How are they determined?

To explain varieties of the social framing of 'scientific' knowledge ideas from neo-institutionalism are helpful. The main argument of neo-institutionalism contradicts Max Weber's idea that organizations produce formal structures in order to attain the highest levels of efficiency, rationality, and predictability. Neo-institutionalists assume that the formal structure of organizations is the outcome of the race for social legitimacy. The starting point for neo-institutionalist organizational sociology is a paper written by Meyer and Rowan (1977). They argued that there is a correlation between cultural patterns and the formal structure of organizations. They interpreted the processes of the creation of formal structures in organizations as a response to the expectations of their social environment. Society and its organizations tend to hold coherent structures. Neo-institutionalists 
call organizations where societal and organizational structures are in balance 'isomorphic' (Meyer and Rowan 1977, 345).

Inspired by the theoretical ideas of Meyer and Rowan (1977), a diverse and heterogeneous set of empirical and theoretical studies has been published deploying the concept of neo-institutionalism in various ways and applying it to different cases. DiMaggio and Powell's (1983) advancement of the concept of isomorphism is of particular interest in understanding the organizational frames of scientific knowledge. They state that isomorphism - the tendency of organizations within a particular field to converge on the model provided by the powerful or successful actor within that field - can be outcome of one or more of three forces: (usually state) coercion, powerful normative pressure groups, or a process of imitation induced by high levels of uncertainty and the presence of leading organizations which show a way to reduce uncertainty.

Drori et al. (2003) apply the ideas of neo-institutionalism to the establishment of scientific institutions in a globalized world. The foundation of similar scientific organizations worldwide at the same time, Drori et al. (2003) argue, cannot be explained exclusively by patterns of rationality, efficiency, or by the need for new findings. Neo-institutionalists explain the globalization of scientific institutions with reference to the fact that they follow a globalized 'powerful social myth' (Meyer and Rowan 1977, 340). This myth refers to all the attributes connected to the term 'modernity':

Science arises and expands in close conjunction with the modern cultural invention and expansion of the model of the rational and purposive social 'actor,' whether individual, organizational, or non-state. For this highly agentic and competent actor, science serves functions far beyond those of an instrumental tool: it plays a broad role analogous to religious ones, providing constitutive and legitimating [...] supports for the hubris involved in claims to actorhood.

(Drori et al. 2003, 23)

Thus, they explain the development of scientific institutions using the ideas of neo-institutionalism. The global spread of cultural patterns like rationalization, secularization, the idea of responsible, independent, and self-convenient actors, etc. contribute to the growing importance of a specific form of science. This 'scientization' (Drori et al. 2003, 23) of the social world contributes to the growth of the authority and power of scientific knowledge in everyday life. It leads to a strong need for legitimation of rights, freedoms, and decisions through scientific knowledge. Legitimation of action is no longer sought in traditional patterns such as those of religion. In a society driven by the myth of modernity, legitimation is sought in rationality. This development takes place on different organizational levels simultaneously: the individual, the organizational, and the governmental level (Drori et al. 2003, 39). For Drori and his co-authors, the expansion of the cultural pattern of modernity means both the geographical spread and the quality and intensity of the saturation of the social world by scientific knowledge. Following this idea, socially legitimated scientific organizations are facilitated by the global spread of cultural patterns - notably, in recent times the pattern of 'Scientization' (Drori et al. 2003, 23).

\section{How empirical economic research became 'scientific'}

I interpret the worldwide and nearly simultaneous foundation of institutions for empirical economic research as the example par excellence for a culturally driven global and social framing of a field of knowledge. By establishing socially legitimated boundaries that are consistent with the global myth of modernity, the products of empirical economic research were transformed into scientific knowledge. The unwritten rules to fulfill the 
demands to be 'scientific' are produced by cultural patterns, and, in the case of empirical economic research, by patterns of rationality and predictability. The simultaneous formation of institutions for empirical economic research in the industrialized world appears as a part of an early globalized 'scientization' of a specific field of economic knowledge.

I conclude that knowledge needs a specific organizational and social frame in order to be legitimated as 'scientific'. The specifications of this frame are defined by social and cultural demands that are - as Drori et al. (2003) point out - produced under the regime of globalized cultural patterns. New cultures produce new strategies of legitimation and diverging frames.

\section{The 'management of economies'}

After concentrating on the socially determined organizational frames I will now turn to the effects political needs have on the transformation of knowledge into 'scientific' knowledge. The argument here is that political institutions must not lose control over some well-defined knowledge areas in society because the legitimation and stability of political institutions are profoundly dependent upon their relationship to science. Here, 'control' does not mean influencing scientific outcomes, but supervising who is, and who is not, a legitimate producer and distributer of such knowledge. Usually the areas concerned are thought to be associated with high risk for a significant part of society. The vital strategy of political institutions in order to maintain control over scientific knowledge is to define the boundaries between scientific and non-scientific knowledge. If political institutions fail to do so societies enter a state called 'civic dislocation' (Jasanoff 1997).

\section{'Civic dislocation'}

In modern societies, no matter whether you characterize them as knowledge societies (Stehr 1994) or risk societies (Beck 1992), scientific knowledge plays an increasingly significant role in social life. It became the leading resource for economic, social, and political power. Generally, one of the significant tasks of political institutions is to distribute and control the major societal resources. Thus, in modern societies political institutions are forced to monitor the use of 'scientific' knowledge too. That in turn means that political institutions have to find ways to control who produces and distributes scientific knowledge and how it is communicated. They have to conciliate the extension of expertise with democratic values and balance technological risks and uncertainties. Sheila Jasanoff, a leading representative of the social studies of science, describes a case where the British government lost all such control over scientific knowledge in 1996 during the so-called bovine spongiform encephalopathy (BSE) crisis, better known as 'mad cow disease' (Jasanoff 1997).

The story Jasanoff reports starts in March 1996 when representatives of the British government informed the public about cases of Creutzfeldt-Jakob disease (CJD) diagnosed in human beings. Contradicting public statements followed regarding the danger of CJD for humans, its connection with BSE and the consumption of beef, and the imminent dangers to the public. Even governmental statements were contradictory. The fact that cases of CJD were diagnosed in human beings glaringly contradicted the government's off-the-shelf formulation that a transmission of BSE from cows to people was impossible. There was no longer reason to trust the government's and its advisors' knowledge of BSE. Instead of defining the problem and offering clear solutions, British political institutions published contradictory opinions oscillating between apocalyptic predictions and implausible minimizations of the problem, or - in the worst case - did nothing. 
It was for such situations that Sheila Jasanoff coined the term 'civic dislocation':

a mismatch between what governmental institutions were supposed to do for the public and what they did in reality. In the dislocated state, trust in government vanished and people looked to other institutions [...] for information and advice to restore their security. (Jasanoff 1997, 223)

'Civic dislocation' is closely connected to the production, the share and the (loss of) control over scientific knowledge as well as with the (refused) dialog about it. The British government lost the monopoly for producing, distributing, and communicating knowledge about a very important - because 'risk'-labelled - issue. What happened after the chaos of public statements and the loss of control over the knowledge distribution was that other, sometimes dubious protagonists appeared who produced and distributed knowledge. Interest groups, supermarket chains, pubs, and butchers began to inform their consumers about the riskiness of eating beef and suggested ways out of the crisis (Jasanoff 1997, 224).

Civic dislocation has at least three broad consequences: first, the 'knowledge vacuum' provokes other institutions to distribute knowledge about the dangers and risks. They move to correct expertise and scientific knowledge by confronting them with so-called common sense or folk wisdom, and in the worst cases use 'old wives' tails'. Secondly, the old institutions' legitimation is contested and their standing is challenged. People are not just interested in a solution to the problem itself but in finding someone to blame for the current 'dislocated' situation. Finally, the old institutions which are expected to produce and distribute knowledge and solutions fall into a paralysis and stop taking action at all (Jasanoff 1997, 223-5).

Jasanoff states that, depending on the social surrounding, there is a variety of strategies to avoid 'civic dislocation'. To regain trust, administrations can count on individual 'trustworthy people' (Jasanoff 1997,227 ) as well as on 'formal processes [...] and [...] styles of reasoning that ensure the transparency and objectivity, if not the wisdom, of governmental decisions' (Jasanoff 1997, 228). I would argue that both strategies are variations on the same theme; namely, building boundaries around a field of knowledge and label it scientific. Politics use the scientization (Drori et al. 2003, 23) of knowledge to produce credibility, trust, and to make their decisions less vulnerable.

\section{The political need for economic knowledge}

What does the notion of 'civic dislocation' mean for the scientification of empirical economic research knowledge in the interwar period? The foundation of empirical economic research institutions illustrates the interdependence of political demands and the creation of 'scientific' knowledge. Historically, the 1920s were the beginning of a new era in economic development. The Great Depression of the 1920s and 1930s showed new dimensions and strengths of economic crisis. Global economic interrelations produced hitherto unseen dimensions of unemployment, uncertainty, and poverty. And it showed that an unstable economy can jeopardize social and political stability. Thus, the economy was discovered as a domain of political intervention. Political institutions had to react to the new dimensions of the economic crisis. They developed the idea of intervening in the economy and started thinking about programmes to plan and to re-animate the economy as a whole. It is not that there was no economic policy per se until then, but it was the dimensions and the size of the target group of economic policy that was new. For the first time political institutions planned to regulate economic processes that affected a 
significant part of the society. No matter if politics tended toward the Keynesian or the liberal state model, it determined to 'manage the economy' (Desrosières 2008, 553).

As economic development becomes increasingly important for the stability of a society, political institutions need legitimated and credible knowledge about it to avoid 'civic dislocation' during economic crisis. As I have shown above, one of the strategies to create that kind of knowledge is to define boundaries around a field of knowledge and label it 'scientific'. That was exactly what happened to empirical economic research in the 1920s. The pre-institutionalized variation of empirical economic research indeed produced knowledge on economic development, but in order to base governmental decisions on it empirical economic research had to acquire another status - it had to become 'scientific'. Empirical economic research connected economic theory with statistical data in order to escape philosophical uncertainties (Mirowski 1989). Thus, it promised to provide scientific solutions for current economic problems (Desrosières 1998, 163).

As already mentioned, political institutions all over the world co-initiated and funded the foundation of empirical economic research departments. They had a vital interest in the 'scientification' of empirical economic knowledge. Thus, political institutions contributed to the transformation of 'normal' knowledge into 'scientific' knowledge about the economic cycles, and economic forecasting was transformed from amateur guesswork into science.

\section{Short Biography}

Werner Reichmann, a sociologist of science, is a Post-Doc Fellow at the Max Planck Institute for the Study of Societies in Cologne (Germany). Before coming to Cologne in 2010 he was Assistant Professor at the University of Konstanz (Germany) and at the University of Innsbruck (Austria). He took his $\mathrm{PhD}$ at the University of Graz (Austria) in 2006. His research focuses on the cultural and social conditions of producing and distributing knowledge about the economic development.

\section{Note}

* Correspondence address: Werner Reichmann, Max Planck Institute for the Study of Societies, Paulstrasse 3, Köln 50676, Germany. E-mail: wr@mpifg.de

\section{References}

Barnes, Barry and Donald MacKenzie. 1979. 'On the Role of Interests in Scientific Change.' Pp. 49-66 in On the Margins of Science: The Social Construction of Rejected Knowledge, edited by Roy Wallis. Keele: University of Keele.

Barnes, Barry and Steven Shapin. 1979. Natural Order: Historical Studies of Scientific Culture. Beverly Hills, CA: SAGE Publications.

Beck, Ulrich. 1992. Risk Society: Towards a New Modernity. London: SAGE Publications.

Bell, Daniel. 1973. The Coming of the Post-Industrial Society: A Venture in Social Forecasting. New York: Basic Books.

Bloor, David. 1976. Knowledge and Social Imagery. London: Routledge \& Kegan Paul.

Brannigan, Augustine. 1981. The Social Basis of Scientific Discoveries. Cambridge: Cambridge University Press.

Callon, Michel. 1986. 'Some Elements of a Sociology of Translation: Domestication of the Scallops and the Fishermen of St Brieuc Bay.' Pp. 196-223 in Power, Action and Belief: A New Sociology of Knowledge? edited by John Law. London: Routledge.

Coenen, Étienne. 1964. La 'Konjunkturforschung' en Allemagne et en Autriche 1925-1933. Louvain: Éditions Nauwelaerts.

Collins, Harry M. 1975. 'The Seven Sexes: A Study in the Sociology of a Phenomenon, or the Replication of Experiments in Physics.' Sociology 9: 205-24. 
Desrosières, Alain. 1998. The Politics of Large Numbers: A History of Statistical Reasoning. Cambridge, MA: Havard University Press.

Desrosières, Alain. 2008. 'Managing the Economy.' Pp. 553-64 in The Cambridge History of Science Vol. 7: The Modern Social Sciences, edited by Theodore M. Porter and Dorothy Ross. Cambridge and London: Cambridge University Press.

DiMaggio, Paul and Walter W. Powell. 1983. 'The Iron Cage Revisited: Institutional Isomorphism and Collective Rationality in Organizational Fields.' American Sociological Review 48: 147-60.

Drori, Gili S., John W. Meyer, Francisco O. Ramirez and Evan Schofer. 2003. Science in the Modern World Polity: Institutionalization and Globalization. Stanford: Stanford University Press.

Drucker, Peter F. 1993. Post-Capitalist Society. New York: Harper Collins Publishers.

Evans, Robert. 1999. Macroeconomic Forecasting: A Sociological Appraisal. London: Routledge.

Fabricant, Solomon. 1984. Toward a Firmer Basis of Economic Policy: The Founding of the National Bureau of Economic Research. NBER Working paper. Retrieved on 25 May 2010 from: http://www.nber.org/nberhistory/ sfabricantrev.pdf.

Gooding, David, Trevor Pinch and Simon Schaffer (eds). 1989. The Uses of Experiment: Studies in the Natural Sciences. Cambridge \& London: Cambridge University Press.

Hess, David. 1997. 'If You're Thinking of Living in STS: A Guide for the Perplexed.' Pp. 143-64 in Cyborgs \& Citadels: Anthropoligical Interventions in Emerging Sciences and Technologies, edited by Gary Lee Downey and Joseph Dumit. Santa Fe: School of American Research Press.

Jasanoff, Sheila. 1997. 'Civilization and Madness: The Great BSE Scare of 1996.' Public Understanding of Science 6: 221-32.

Jasanoff, Sheila (ed.). 2004. States of Knowledge: The Co-Production of Science and Social Order. London \& New York: Routledge.

Jones, Kit. 1999. 'Sixty Years of Economic Research. A Brief History of the National Institute of Economic and Social Research.' NIESR Occasional Papers 52, 72 pp.

Knoblauch, Hubert. 2005. Wissenssoziologie. Konstanz: UVK.

Knorr, Karin. 1977. 'Producing and Reproducing Knowledge: Descriptive or Constructive? Toward a Model of Research Production.' Social Science Information 16: 669-96.

Knorr Cetina, Karin. 1981. The Manufacture of Knowledge. Oxford: Pergamon Press.

Knorr Cetina, Karin. 1995. 'Laboratory Studies - The Cultural Approach to the Study of Science.' Pp. 140-66 in Handbook of Science and Technology Studies, edited by Sheila Jasanoff, Gerald E. Markle, James C. Petersen and Trevor Pinch. London: SAGE Publications.

Knorr Cetina, Karin. 1999. Epistemic Cultures: How the Sciences Make Knowledge. Cambridge, MA \& London: Harvard University Press.

Knorr Cetina, Karin. 2007. 'Culture in Global Knowledge Societies: Knowledge, Cultures, and Epistemic Cultures.' Interdisciplinary Science Reviews 32: 361-75.

Krengel, Rolf. 1986. Das Deutsche Institut für Wirtschaftsforschung. Berlin: Duncker und Humblot.

Kuhn, Thomas. 1962. The Structure of Scientific Revolutions. Chicago: The University of Chicago Press.

Kulla, Bernd. 1996. Die Anfänge der Empirischen Konjunkturforschung in Deutschland 1925-1933. Berlin: Duncker und Humblot.

Lane, Robert E. 1966. 'The Decline of Politics and Ideology in a Knowledgeable Society.' American Sociological Review 31: 649-62.

Latour, Bruno and Steve Woolgar. 1979. Laboratory Life: The Construction of Scientific Facts. Princeton, NJ: Princeton University Press.

Lynch, Michael. 1985. Art and Artifact in Laboratory Science: A Study of Shop Work and Shop Talk in a Research Laboratory. London: Routledge \& Kegan Paul.

MacKenzie, Donald A. 1981. Statistics in Britain 1865-1930: The Social Construction of Scientific Knowledge. Edinburgh: Edinburgh University Press.

Mannheim, Karl. 1929. Ideologie und Utopie. Bonn: Cohen.

Merton, Robert K. 1938. 'Science and the Social Order.' Philosophy of Science 5: 321-37.

Meyer, John W. and Brian Rowan. 1977. 'Institutionalized Organizations: Formal Structure as Myth and Ceremony.' American Journal of Sociology 83: 340-63.

Mirowski, Philip. 1989. 'The Probabilistic Counter-Revolution, or How Stochastic Concepts Came to Neoclassical Economic Theory.' Oxford Economic Papers 41: 217-35.

Mulkay, Michael. 1979. Science and the Sociology of Knowledge. London: G. Allen and Unwin.

Pickering, Andrew. 1984. Constructing Quarks: A Sociological History of Particle Physics. Chicago: University of Chicago Press.

Reichmann, Werner. 2007. “Die Gezeiten der Wirtschaft': Institutionalisierung und Methoden der Beobachtung Wirtschaftlicher Zyklen in Österreich bis 1945.' Österreichische Zeitschrift für Geschichtswissenschaft 18: 39-58.

Reichmann, Werner. 2010. Die Disziplinierung des Ökonomischen Wandels: Soziologische Analysen der Konjunkturforschung in Österreich. Marburg: Metropolis-Verlag. 
Rutherford, Malcolm. 2005. 'Who's Afraid of Arthur Burns?' - The NBER and the Foundations.' Journal of the History of Economic Thought 27: 109-39.

Shapin, Steven and Simon Schaffer. 1989. Leviathan and the Air-Pump: Hobbes, Boyle, and the Experimental Life. Princeton: Princeton University Press.

Shils, Edward. 1970. 'Tradition, Ecology, and Institution in the History of Sociology.' Daedalus 99: 760-825. Sismondo, Sergio. 1993. 'Some Social Constructions.' Social Studies of Science 23: 515-53.

de Solla Price, Derek J. 1963. Little Science, Big Science... And Beyond. New York: Columbia University Press.

Stehr, Nico. 1994. Knowledge Societies. London, Thousand Oaks \& New Delhi: SAGE Publications.

Zenzen, Michael and Sal Restivo. 1982. 'The Mysterious Morphology of Immiscible Liquids: A Study of Scientific Practice.' Social Science Information 21: 447-73. 